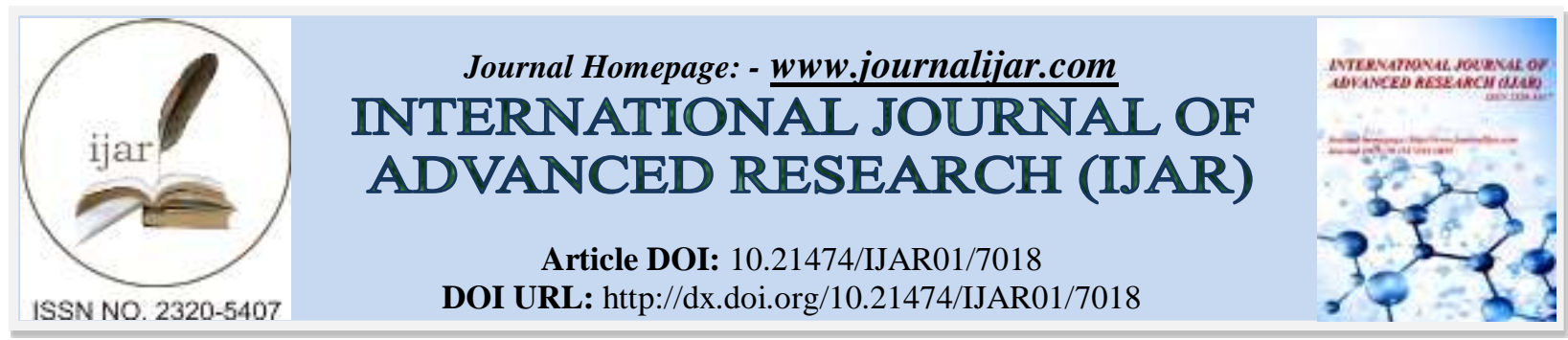

RESEARCH ARTICLE

\title{
DETERMINATION OF COPPER, IRON, AND NICKEL IN SERUM OF MYOCARDIAL INFARCTION PATIENTS BY FLAME ATOMIC ABSORPTION SPECTROMETRY.
}

\author{
Alaa Abbas Ibadi ${ }^{1}$, Dawood S. Ali ${ }^{2}$ and Hassan Thamir Abdulsahib ${ }^{2}$. \\ 1. Department of chemistry, college of science, Missan University, Missan, Iraq. \\ 2. Department of chemistry, college of science, Basrah University, Basrah, Iraq.
}

\section{Manuscript Info}

Manuscript History

Received: 02 March 2018

Final Accepted: 04 April 2018

Published: May 2018

\begin{abstract}
Trace elements may play an vital role in the development of MI. The differences between the concentration of Copper, Iron, and Nickel that has occurred during the Myocardial Infarction by the determination of the concentration of these elements in both patients and healthy control subjects. The study included 60 number of cases of MI and equal number of matched healthy control. The results shows an increasing in the levels of all tested elements $\mathrm{Cu}, \mathrm{Fe}, \& \mathrm{Ni}$ with $(\mathrm{P}<0.05)$ in $\mathrm{MI}$ patients which are found to be statistically significant. In addition, we found slight differences in the elements concentration when compared according to the gender.
\end{abstract}

Copy Right, IJAR, 2018,. All rights reserved.

\section{Introduction:-}

Myocardial infarction (MI) defined as death or necrosis of myocardial cells. It is a diagnosis at the end of the spectrum of myocardial ischemia or acute coronary syndromes (1). Over the past 50 years, studies on the effect of trace elements in health and disease have led to a good interpretation of their mechanism and essentiality to the life (2).

Trace elements are those found in such small quantities in the living tissues, they are plays a vital role in the structure of proteins, enzymes, and complex carbohydrates to contribute in the biological reactions. Copper and Iron considered a part of the trace elements that appear in the body as essential trace elements, these elements are involved in a number of metabolic activities, including neuroconduction, transport, excretory processes and serving as cofactors for enzymes. (3)(4)

Serum levels of trace elements maybe altered in patients with CAD. The higher or lower levels may be both a cause and effect of atherosclerosis or the result of another unknown parameter (5).

Copper is an important trace element and is associated with a number of metalloproteins (6). Because metals can cause oxidative modification of low density lipoprotein cholesterol and the formation of free radicals, the effect of several prooxidant metals, including copper, on cardiovascular disease has come under investigation, studies support the possibility that increased copper concentration may increase the risk for cardiovascular disease (7). Also Iron is a metal that may be important role in the catalytic reaction and reduction reactions, Epidemiological studies have shown that there are relationship between serum iron levels and Ischemic Heart Disease (IHD) (8). In addition to acceleration of the lipid peroxidation, iron through increase of hemoglobin and hematocrit levels, by increasing the viscosity of blood and thus increasing the probability of thrombogenic effects may increase the risk of MI (9). 
Nickel, in addition to Copper and Iron, also can act an important role in human health, it is an essential nutrient for human. The toxic effects of metals, such as Nickel, and its relation to cardiac damage should be establish urgently, the free radical-mediated cellular damage and reactive oxygen species (ROS) contribute to the Nickel mechanism of toxicity, recent investigation that the free radicals may be important contributors to cardiac dysfunction (10).

Nickel is known to bind to specific proteins and/or amino acids in the blood serum and the placenta. These ligands are instrumental in the transport and distribution of nickel in the body. Nickel is not destroyed in the body, but its chemical form may be altered. The metabolism of nickel is most appropriately viewed in light of its binding to form ligands and its transport throughout the body. Various disease states (myocardial infarction and acute stroke) and injuries (burn injury) are associated with altered transport and serum concentrations of Nickel (11).

Determination of the Trace elements in blood serum becomes very important to investigate their vital role in human metabolism, as well as to achieve information concerning with the health status of individuals (12).

This study included the investigation the differences between the concentration of Copper, Iron, and Nickel that has occurred during the Myocardial Infarction by the determination of the concentration of these elements in both patients and healthy control subjects.

\section{Material and Methods:-}

All chemicals used in this study with highly purified material and no farther purification done.

\section{Sample collection and analysis:-}

Venous blood samples of $(5 \mathrm{ml})$ drawn from patients of MI, The blood was allowed to clot at $37{ }^{\circ} \mathrm{C}$ for $10-15$ minutes, and then centrifuged in (402 X g) for approximately 10-15 minutes then the sera were obtained and stored at $0{ }^{\circ} \mathrm{C}$ until analysis.

\section{Determination of serum levels of trace elements:-}

Serum concentrations of $\mathrm{Cu}, \mathrm{Fe}$, and Ni were determined by using Flame Atomic Absorption Spectrometry (AAS), determination method is based on the principle that atoms of the element when aspirated into AAS vaporized and absorbed light of the same wavelength as the emitted by the element when in the excited state.

\section{Statistical Analysis:-}

Data were analysed by using SPSS software (Version 19) and the values were expressed as mean and standard deviation. Pearson's correlation analysis was carried out. All comparison were 2-tailed, and p value of $<0.05$ or $<0.01$ were considered significant

\section{Results:-}

From 60 patients with Myocardial Infarction, 35 (58.33\%) subject were males and 25 (41.66\%) were females. The average age of patient's males and females were 54.75 \pm 14.9 and $62.08 \pm 12.0$ years, respectively. From 60 healthy group, $37(61.66 \%)$ subject were males and $23(38.33 \%)$ were females. The average age of healthy males and females were $40.59 \pm 14.3$ and $40.59 \pm 13.3$ years, respectively.

A comparison of levels of Copper, Iron, and Nickel in study cases shown below in the Table 1, also the Table 2 shows a comparison of levels of Copper, Iron, and Nickel in study cases according to the gender. Also Figure 1 shows the comparison of levels of Copper, Iron, and Nickel in study cases, Figures 2,3, and 4 shows the Concentration of Copper, Iron, and Nickel related to life spans, finally, Figure 5 shows Copper, Iron and Nickel concentration related to the gender.

Table 1:- comparison of levels of Copper, Iron, and Nickel in study cases

\begin{tabular}{|l|l|l|l|}
\hline Parameter $(\mu \mathrm{g} / \mathrm{ml})$ & Controls & Patients & $\mathrm{P}$-Value \\
\hline Copper & $0.929 \pm 0.544$ & $1.375 \pm 0.604$ & $\mathrm{P}<0.05$ \\
\hline Iron & $2.862 \pm 1.38$ & $4.297 \pm 0.202$ & $\mathrm{P}<0.05$ \\
\hline Nickel & $2.539 \pm 1.616$ & $6.381 \pm 1.44$ & $\mathrm{P}<0.05$ \\
\hline
\end{tabular}

Values reported as mean \pm Standard deviation (SD); $n=$ no. of cases $\mathrm{P}<0.05$ highly significant 


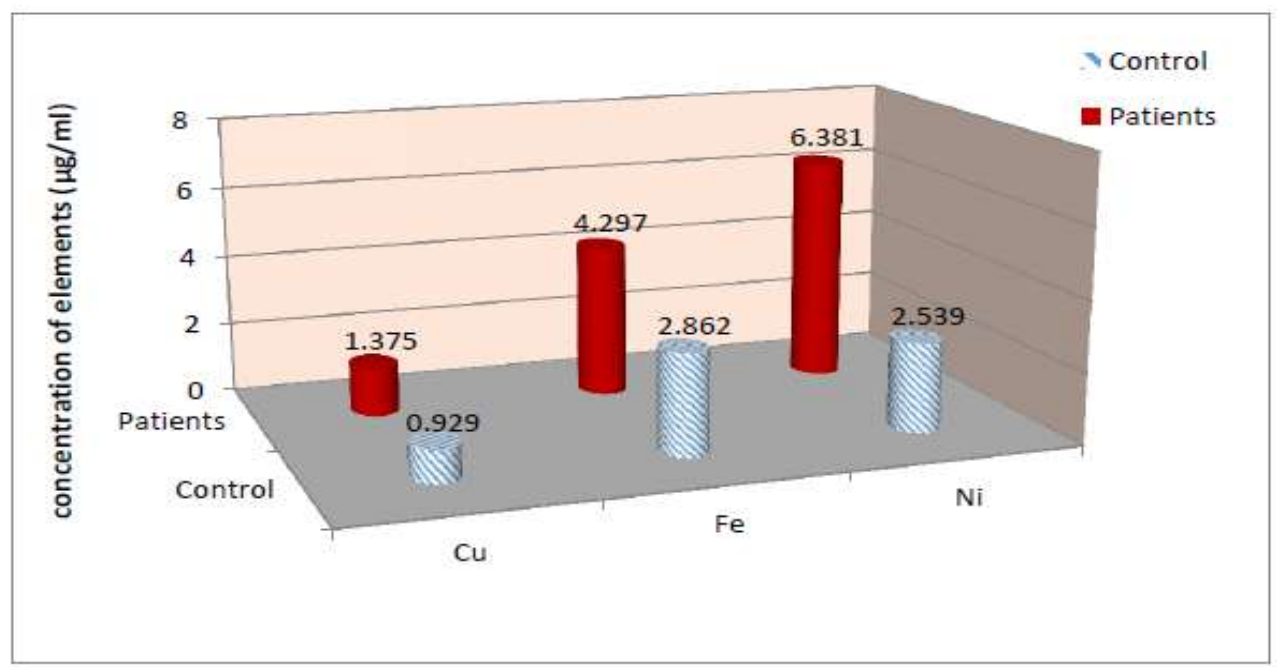

Figure 1:- comparison of levels of Copper, Iron, and Nickel in study cases

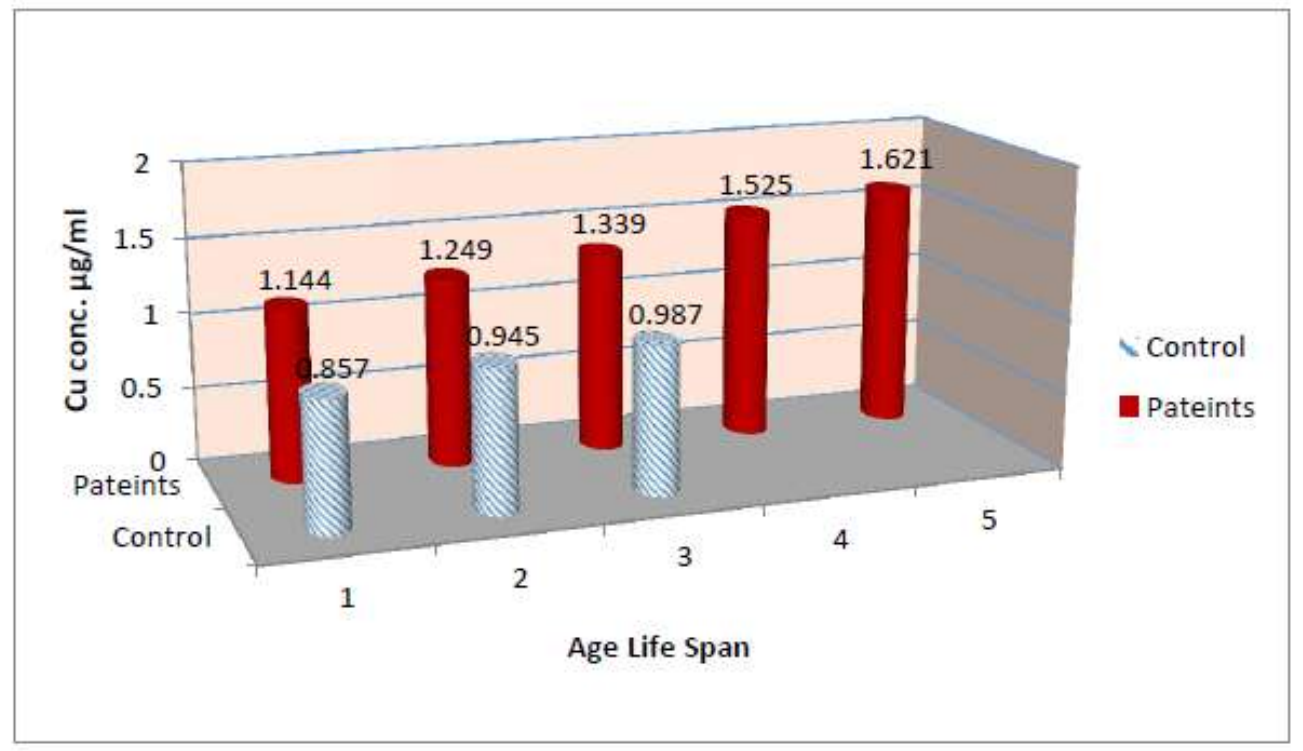

Figure 2:- Concentration of Copper related tolife spans 


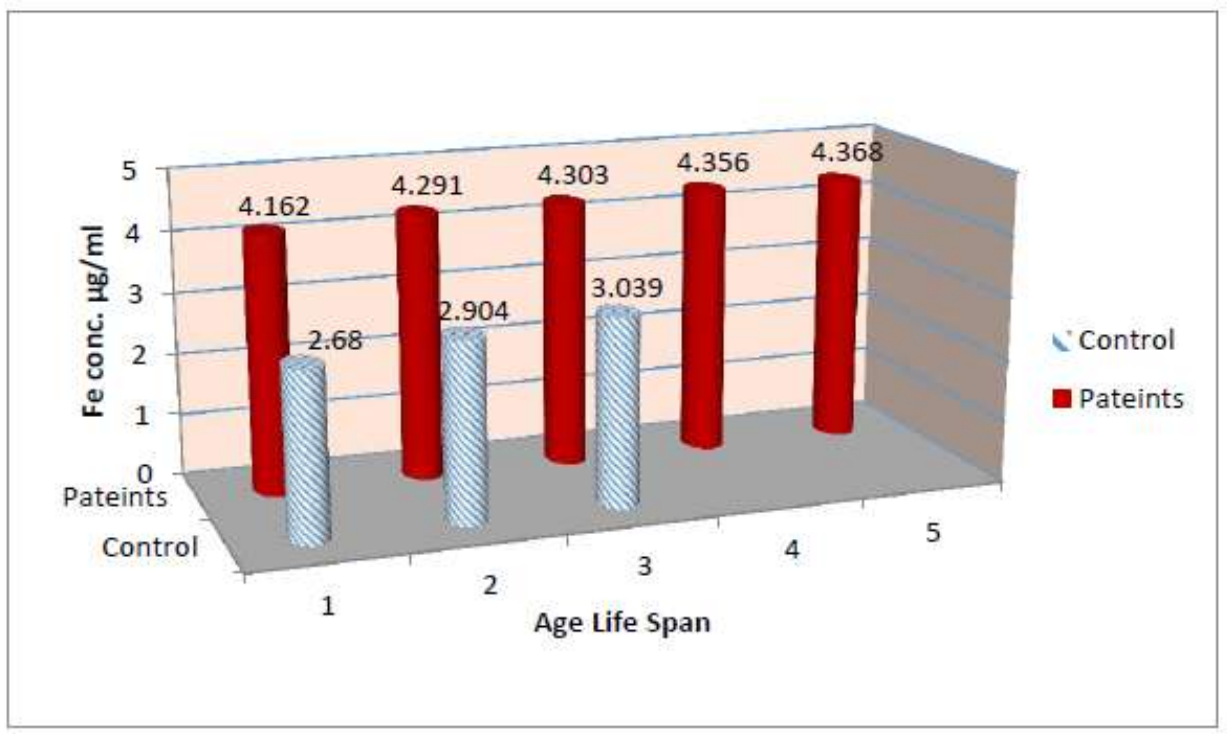

Figure 3:- Concentration of Iron related to life spans

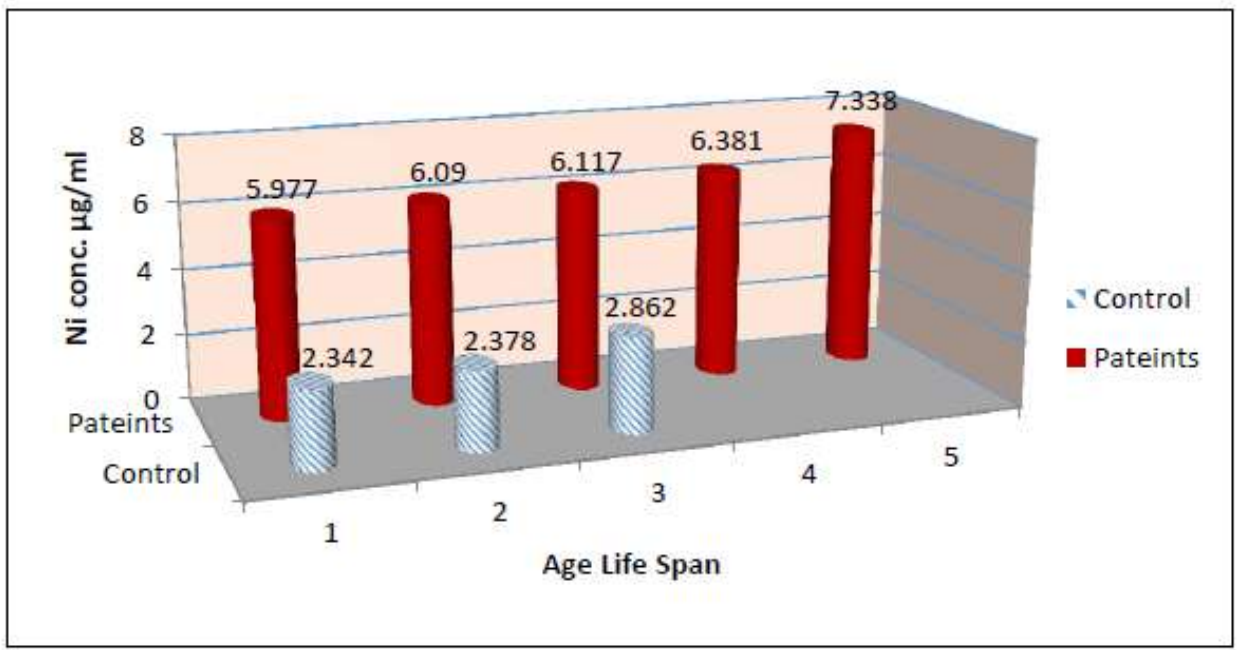

Figure 4:- Concentration of Nickel related to life spans

Table 2:- comparison of levels of Copper, Iron, and Nickel in study cases according to the gender

\begin{tabular}{|l|l|l|l|l|l|l|}
\hline \multicolumn{1}{|l|}{ Case } & \multicolumn{5}{l}{ Control } & Patients \\
\cline { 2 - 7 } Gender & $\mathrm{Cu}$ & $\mathrm{Fe}$ & $\mathrm{Ni}$ & $\mathrm{Cu}$ & $\mathrm{Fe}$ & $\mathrm{Ni}$ \\
\hline \hline Male & $0.865 \pm 0.539$ & $3.161 \pm 1.40$ & $2.452 \pm 1.67$ & $1.360 \pm 0.65$ & $4.333 \pm 0.19$ & $6.261 \pm 1.48$ \\
\hline Female & $1.043 \pm 0.550$ & $2.695 \pm 1.36$ & $2.695 \pm 1.53$ & $1.394 \pm 0.53$ & $4.270 \pm 0.20$ & $6.540 \pm 1.39$ \\
\hline P-value & $\mathrm{P}<0.05$ & $\mathrm{P}>0.05$ & $\mathrm{P}>0.05$ & $\mathrm{P}>0.05$ & $\mathrm{P}>0.05$ & $\mathrm{P}>0.05$ \\
\hline
\end{tabular}

Values reported as mean \pm Standard deviation $(\mathrm{SD}) ; \mathrm{n}=$ no. of cases. $\mathrm{P}<0.05$ highly significant 


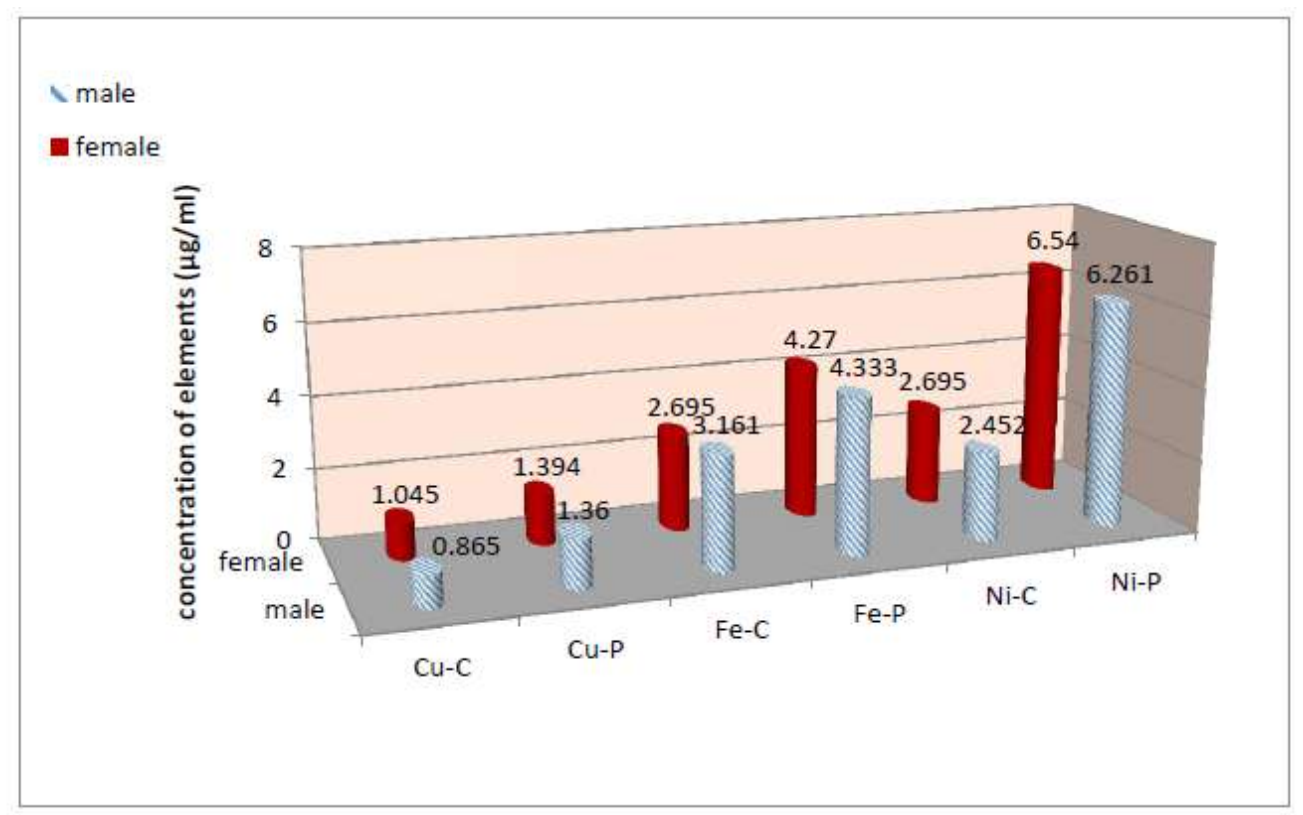

Figure 5:- Copper, Iron and Nickel concentration related to the gender

\section{Discussion:-}

Our results shows a highly significant increase in the concentration of Copper, Nickel and Iron in myocardial infarction patients' compared with healthy controls.

A highly significant increase observed in the levels of Copper concentrations in the sera of patients compared with healthy control subjects. The increasing in the Copper levels may be due to rise in the Copper binding capacity of ceruloplasmin which is a Copper containing enzyme and acute phase reactant, also may be due to the injury and subsequent necrosis of myocardial cells. Increased serum Copper levels are a part of a specific defense mechanism to provide more Copper at the site of infarction to reduce its size and the extent damage (13) (14).

It is well known that copper plays a vital role in oxidative stress in which copper in its free form is a potent cytotoxic element because of its redox chemistry. It readily participates in Fenton and Heiber Weiss reactions to generate reactive oxygen species, a high level of copper enhances the toxic effect of metal dependent free radicals (15).

In addition, it acts as pro-oxidants and may participate in metal catalysed formation of free radical, it is very potent to generate reactive oxygen species (ROS) after a reaction with oxygen. Free $\mathrm{Cu}(\mathrm{II})$ ion can interact with hydrogen peroxide $\left(\mathrm{H}_{2} \mathrm{O}_{2}\right)$ leading to the formation of the deleterious hydroxyl radical via the Fenton reaction. Bound to proteins, copper is generally less susceptible to participate in the Fenton reaction (16)

The second element in our study is Iron, which plays an important role in heart disease, the relationship of serum Iron status and cardiovascular disease was demonstrated by the epidemiological studies.

Iron concentrations was significantly higher in the patients whom suffering from myocardial infarction compared to heathy control that's agree with the studies of (Rostami M. et al; 2013), (Vijaya L. et al;2016), and (Pradhan D.P. et al;2016).

Iron is a transition metal, which can important role in the catalytic reaction of poisons, reduction reactions and is involved in many biological processes and harmful diseases to humans. Excess iron of body is a risk factor for incidence of CVD (17)

Also, Iron induced oxidative stress in the form of increased generation of reactive oxygen species (ROS), in a series of Fenton like reactions, it's through increase of lipid peroxidation and increased of haemoglobin and haematocrit levels and therefore increasing the viscosity of blood and increasing the likelihood of thrombogenic effects, can 
increase the risk of myocardial infarction. It is the free ionic form of iron that is harmful due to its pro-oxidative properties, which generates reactive free radicals Superoxide produced during oxidative stress can mobilize free catalytic iron from ferritin and facilitate the formation of Hydroxyl ion. Reactive oxygen species, superoxide cause lipid peroxidation and endothelial dysfunction in vessels (18)(9).

In addition to Copper and Iron effect in myocardial infarction case, also Nickel plays a vital role in this case, the rapid increase in the concentration of nickel in the blood may perhaps be used as a diagnostic indicator of recent myocardial infarction, that's according to study of (Hegde et al., 1961)

Nickel may bind to DNA-repair enzymes and generate oxygen-free radicals to cause protein degradation in situ. This irreversible damage to the proteins involved in DNA repair, replication, recombination, and transcription could be important for the toxic effects of nickel (19)

$\mathrm{Ni}$ (II) can also generate free radicals from lipid hydroperoxides in the presence of several oligopeptides. Hence, free radical generation from the reaction of $\mathrm{Ni}$ (II)-thiol complexes and molecular oxygen, and/or lipid hydroperoxides, could play an important role in the mechanism(s) of $\mathrm{Ni}$ (II) toxicity. The results of a series of studies using cultured human peripheral blood lymphocytes also suggest that nickel induces oxidative stress in humans (20-22)

Our results shows a high significant increasing in Nickel concentrations in patients compared with controls, which agree with a study of (Charies N. L. et al 1985) which also observed an increase in Nickel concentrations in the sera of patients with myocardial infarction, their study hypotheses three explanations for this increasing:-

First, the myocardium or coronary arteries of patients may contain abnormally increased concentrations of nickel and when stunned by ischemia, may release nickel into the circulation.

Second, hypernickelemia may be a secondary phenomenon, mediated by release of nickel from another organ, in response to stress, the lung would be a likely source of nickel, because human lung tissue accumulates nickel with advancing age

Third, nickel may be bound to clotting factors or complement components, and released into serum during the coagulation cascade that occurs during coronary thrombosis or during the activation of the alternative complement pathway that follows myocardial inflammation. (23)

Also we compared our results as a life spans, we found an increase in serum Copper concentration during age that's agree with study of Yunice et al.,1974 (24).So we observed an increase in Iron and Nickel concentration during age life spans, that's corresponds to studies shown that age accompanied by increasing Iron levels (25). So Nickel accumulates with advance aging, that's agree with our results.(23)

When we compared our results according the gender, we found the females have a higher Copper and Nickel concentrations compared with males in both cases patients and healthy control, and the opposite will found in Iron concentration, which tend to be higher in males than females in both patients and healthy control subjects.

The increase in Copper concentration in females can be attributed to estrogen, a hormone which alters the distribution of copper in the liver and increases its plasmatic levels (26).

It is generally considered that women, especially before menopause, have lower levels of iron stores than agematched men. Although periodic iron loss (menstruation) or childbirth has long been, consider the protective mechanism against Iron overload in women (27).

A slight increase in Iron concentrations observed in male patients compared with females, this can attributed to the fact that nearby $80 \%$ of the females in our study are over the age 50 years, in menopause, it is expected that there will be convergence of iron concentration in both sexes and therefore Copper as well.

The normal ranges of nickel concentrations in body fluids or tissues (serum, blood, lung, and kidney) are not significantly influenced by age, sex, or pregnancy (28). 
In our study, a very slight difference observed in Nickel concentrations in males and females in both cases. Females of all ages, children, youths, and adults are more exposed to Nickel than men are, that maybe due to direct and prolonged skin contact with items that release nickel ions. The causes vary on fashion and other factors in8uencing exposure. Cheap jewellery, precious-metal jewellery, watches, spectacle frames, buckles (29).

\section{Conclusion:-}

It is concluded that the trace elements such Copper, Iron, and Nickel considered being a major risk factor for myocardial infarction. The results of the present study confirm the hypothesis that the increasing in the levels of both Copper and Iron catalyse the Fenton reaction in generation of free radicals, also Nickel have the ability to generate free radicals from lipid hydroperoxides in the presence of several oligopeptides, which in turn increase free radical mediated oxidative stress.

\section{Acknowledgements:-}

The researcher would like to thank all the team, doctors, nurses, laboratory technician, in the Al-Sader technical hospital and Basrah General Hospital for their kind assistance and providing facilities during data and samples collection procedure. The authors also would like to express thanks to Asst. Prof. Safaa S. Najim for his helpful comments on the manuscript.

\section{References:-}

1. Rubin E, Farber JL, Eds. Essential Pathology. Philadelphia, PA: JB Lippincott Co; (1995)

2. Yavuz B, Ertugrul DT, Cil H, et al. Increased Levels of 25 Hy-droxyvitamin D and 1,25-Dihydroxyvitamin D After Rosuvas-tatin Treatment: A Novel Pleiotropic Effect of Statins? Cardio-vasc Drugs Ther. (2009); 20: 312320.

3. Nagat SM. Trace elemen imbalance in mild and severe psoriasis: A new insight in biomarker diagnostic value for psoriasis. Our Dermatol Online, (2013); 4(4): 449-452.

4. Ramprasad N, Mohammed A. Role of Trace Elements and Lipid Peroxidation levels in pre and post Hemo Chronic renal failure patients. Inter J of Res in Biochem and Biophysics, (2013); 3(1): 1-6.

5. Aysegul Cebi1, Yuksel Kaya, Hasan Gungor, Halit Demir, Ibrahim Hakki Yoruk, Nihat Soylemez, Yilmaz Gunes, Mustafa Tuncer, Trace Elements, Heavy Metals and Vitamin Levels in Patients with Coronary Artery Disease, Int. J. Med. Sci.; (2011). 8(6):456-460

6. Shenkin A, Baines M Vitamins and Trace Elements. In: Burtis CA, Ashood ER, Bruns DE, (eds). TIETZ Fundamentals of Clinical Chemistry. Philadelphia: (2008) Saunders 476-508.

7. Kinsman GD, Howard AN, Stone DL, et al. Studies in copper status and atherosclerosis. Biochem See Trans (1990); 18:1186-8.

8. R. Gupta, S. Rastogi, R. Nagar et al., Dietary and serum iron, body iron stores and coronary heart disease. (2000) J. A PI. 48, 489.

9. S. B. Sharma, S. Dwivedi, N. Kumar et al., Studies on oxidative stress, serum iron and iron binding capacity in subjects prone to the risk of coronary artery disease. Ind. Heart (2000) J. 583.

10. E.L.B.Novelli, Y.S.Diniz, T.Machado, V.ProenCa, T.TibiriCA, L.Faine,'Toxic mechanism of Nickel exposure on cardiac tissue".journal Toxic Substance Mechannisms.(2015).p177-187

11. ATSDR (Agency for Toxic Substances and Disease Registry). Toxicological profile for nickel. Atlanta, GA, USA: ATSDR/ U.S. Public Health Service, ATSDR/TP-88/19; (1988).

12. Mitiko Saikia, Omar Jaluulb, Nairo Massakazu Sumitac, Marina Beatriz, Agostini Vasconcellosa, Wilson Jacob Filho, Trace element contents in serum of healthy elderly population of metropolitan Paulo area in Brazil, Journal of Trace Elements in Medicine and Biology, (2007) 21, S1, 70-73

13. Joachim Manthey, Markus Stoeppler, Wolfgang Morgenstern, Egbert Nossel, Dieter Opherk, Andrea Weintraut, et al. Associations Between Blood Levels and Angiographic Findings,(1981);64:722-729.

14. Tan LK, Chua KS, Toh AK : Serum magnesium, copper and zinc concentrations in acute myocardial infarction. J Clin Lab Anal (1992); 6: 324-328.

15. Evans JL, Goldfine ID, Maddux BA, Grodsky GM Oxidative stress and stress-activated signaling pathways: A unifying hypothesis of type 2 diabetes. Endo Rev (2002) 23: 599-622.

16. Marjolaine R, Philippe R, Nihar R ,Evelyne T, Emmanuel B, The antioxidant properties of serum albumin, FEBS Letters, (2008) 582: 1783-1787

17. S. K. Sivaraman, G. Zachariah, and P. T. Annamalai, Serum free iron as a risk factor for acute myocardial infarction. Kuwait Medical Journal (2002) 34, 217. 
18. Marks ${ }^{e e}$ Basic Medical Biochemistry, A Clinical Apporoach.4th Edition. chap 24,oxygen toxicity and free radical injury (2013);P.440.

19. Lynn S, Yew FH, Chen KS, Jan KY. Reactive oxygen species are involved in nickel inhibition of DNA repair. Environ Mol Mutagen (1998); $29:$ 208-16.

20. Chen CY, Huang YF, Lin YH, Yen SF. Nickel-induced oxidative stress and effect of antioxidants in human lymphocytes. Arch Toxicol (2003); 77 : 123-30.

21. Chen CY, Huang YF, Huang WR, Huang YT. Nickel induces oxidative stress and genotoxicity in human lymphocytes. Toxicol Appl Pharmacol (2003); 189: 153-9.

22. M'Bemba-Meka P, Lemieux N, Chakrabarti SK. Role of oxidative stress and intracellular calcium in nickel carbonate hydroxide-induced sister-chromatid exchange, and alterations in replication index and mitotic index in cultured human peripheral blood lymphocytes. Arch Toxicol (2007); $81: 89-99$.

23. Charles N. Leach Jr. Jeanne V. Linden, Sidney Sunderman Jr. M. Kopfer, M. Cristina Crisostomo, and F. William. Nickel Concentrations in Serum of Patients with Acute Myocardial Infarction or Unstable Angina Pectoris. CLIN.CHEM. (1985) 31/4, 556-560.

24. Aniece A. Yunice, PhD, Robert D. Lindeman, MD, Anthony W. Czerwinski, MD, and Mervin Clark, MD. Influence of Age and Sex on Serum Copper and Ceruloplasmin Levels. Journal of Gerontology 1974, Vol. 29, No. 3, 277-281

25. McMillin GA. Pediatric reference intervals for serum copper and zinc. Clin Chim Acta. (2012);413:612-5.

26. Dallman PR, Siimes MA, Stekel A. Iron deficiency in infancy and childhood. Am J Clin Nutr (1980); 33:86118.

27. Bedwal RS, Bahuguna A. Zinc, copper and selenium in reproduction Experientia. (1994);50(7):626-40.

28. Paul Hahna, Gui-shuang Yingb, John Beardc and Joshua L. Dunaief a . Iron levels in human retina: sex dicerence and increase with age. VISION, RETINA NEUROREPORT. (2006) Vol 17 No 1727

29. Satish Kumar and A.V. Trivedi*. A Review on Role of Nickel in the Biological System. Int.J.Curr.Microbiol.App.Sci (2016) 5(3): 719-727

30. M. Vahter,* M. Berglund,* A. As kesson,* and C. LideHn. Metals and Women's Health. Environmental Research Section A (2002) 88, 145\}155.

31. Aniece A. Yunice, PhD, Robert D. Lindeman, MD, Anthony W. Czerwinski, MD, and Mervin Clark, MD. Influence of Age and Sex on Serum Copper and Ceruloplasmin Levels. Journal of Gerontology 1974, Vol. 29, No. 3, 277-281 